\section{COLOR ATLAS OF ORAL DISEASES: DIAGNOSIS AND TREATMENT, 4th edn}

G Laskaris

Thieme, 2017

ISBN 9783137170044 pp 690 Price €169.99 $£ 151.50$

The title probably tells you all you need to know about this book, but I will persist with this review. This is the fourth edition of a book that first appeared nearly 30 years ago, initially in the Greek language, but was translated into English for three subsequent editions (mind you, it has also been published in seven more languages!). The Preface tells us that the latest version contains 10 new chapters, and that the illustrations are extensively revised and improved. I would not be surprised. This is indeed a fine atlas, but far more than just a picture book.

The opening page filled me with nostalgia. It illustrates a Nikon $35 \mathrm{~mm}$ medical camera, a beautiful piece of obsolete work, with a lens and ring flash to simply die for. The author of this book has used this for 43 years and amassed a collection of 130000 images. My 3000 slides, mostly of ears, do not quite compare. Unfortunately, it is getting harder to even find $35 \mathrm{~mm}$ slide film now, let alone a projector, and the very best slide digitisers are mind-numbingly slow. My Dental Eye II camera was very similar, bought for $£ 800$ in the late 1980 s and worth approximately $£ 35$ on eBay now. It finally went to a charity shop, as no-one wanted it.

It is fortunate that the title speaks for itself as, so far, I have managed to tell you nothing about the book, I admit. Well, there are over 1000 superb quality illustrations, mostly of intra-oral pathology, but with plenty of head and neck, dermatology, and even genitourinary medicine images. The last are not for the squeamish and do encourage a life of celibacy, trust me. For every disease illustrated, there is an excellent and concise text summarising, in turn, key points, an introduction (telling us about the disease), clinical features (how to recognise it), differential diagnoses, pathology and treatment. I found this format ideal for browsing and, on countless occasions, found myself ashamed that, after 40 years in ENT, 'I did not know that'.

Our clever colleagues in oral and maxillofacial surgery have the experience that allows them to gaze upon a lesion, stretch the mucosa, prod it and wipe the surface, and immediately offer a diagnosis. This book, of course, shows all the classical diseases that the novice needs to see, but also some of the rarest (but rather photogenic) disorders. It is fascinating to see the oral manifestations of what are primarily

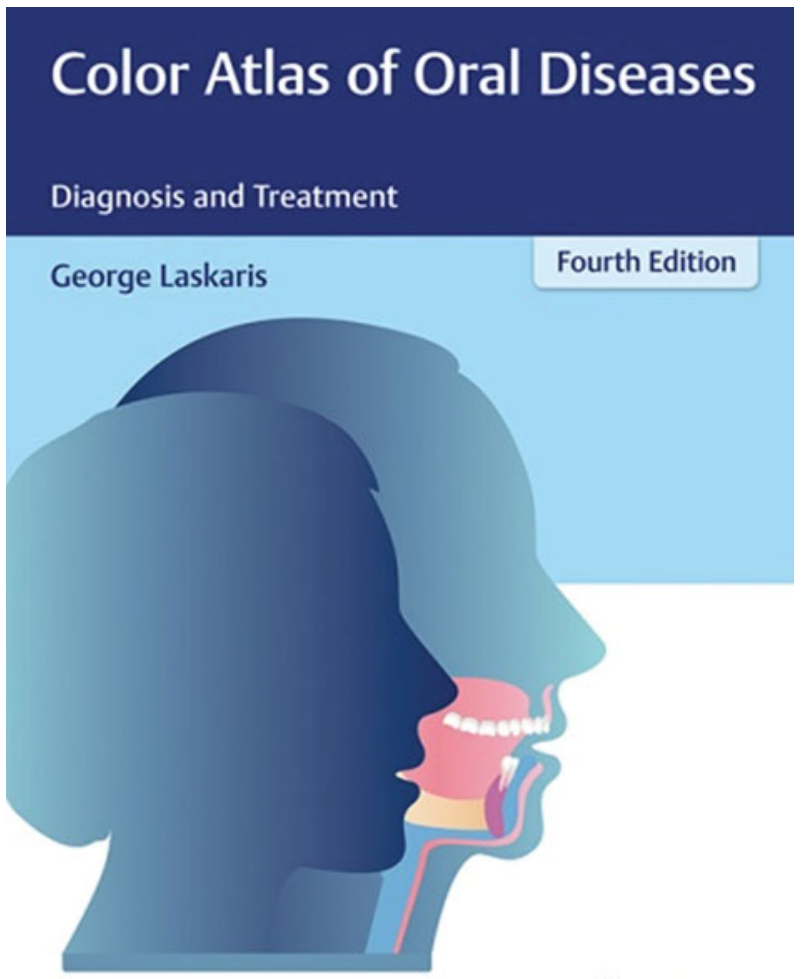

埢Thieme

systemic problems, such as dermatological, gastrointestinal, metabolic or syndromal diseases, each covered in dedicated chapters. Infectious processes, and especially human immunodeficiency virus related disorders, autoimmunity and neoplasms, benign or malignant, obviously dominate the coverage.

A really clever appendix was easily missed, but invaluable. Terminology of lesions requires precise definition and, after reading this, I can now distinguish a macule from a papule. Then, once the morphology is decided, there is a list of every possible cause. Then take a look at the colour (or even 'color'). I now know there are 15 causes of a yellow lesion, 9 for a white one that can be scraped off the underlying mucosa and dozens for those that cannot be. Even the closing section is well thought out, guiding us on how to biopsy a lesion according to its morphology.

ENT trainees (indeed, a part-time senior otologist, whose work now almost solely comprises screening for ENT cancers) tend not to see these sorts of presentations, thanks to the industry of our colleagues in oral surgery. Pattern recognition is everything, so the atlas is invaluable and the text does live up to the subtitle. I learnt a lot from this, a bit late in my career alas.

L M FLOOD

Middlesbrough, UK 